\title{
Si-to-Si wafer bonding using evaporated glass
}

\section{Reus, Roger De; Lindahl, M.}

\section{Published in:}

Solid State Sensors and Actuators, 1997. TRANSDUCERS '97 Chicago., 1997 International Conference on

Link to article, DOI:

10.1109/SENSOR.1997.613738

Publication date:

1997

Document Version

Publisher's PDF, also known as Version of record

Link back to DTU Orbit

Citation (APA):

Reus, R. D., \& Lindahl, M. (1997). Si-to-Si wafer bonding using evaporated glass. In Solid State Sensors and Actuators, 1997. TRANSDUCERS '97 Chicago., 1997 International Conference on (pp. 661-664). IEEE. https://doi.org/10.1109/SENSOR.1997.613738

\section{General rights}

Copyright and moral rights for the publications made accessible in the public portal are retained by the authors and/or other copyright owners and it is a condition of accessing publications that users recognise and abide by the legal requirements associated with these rights.

- Users may download and print one copy of any publication from the public portal for the purpose of private study or research.

- You may not further distribute the material or use it for any profit-making activity or commercial gain

- You may freely distribute the URL identifying the publication in the public portal 


\title{
Si-to-Si wafer bonding using evaporated glass
}

\author{
Roger de Reus and Michael Lindahl \\ Mikroelektronik Centret, DTU bldg. 345-East, DK-2800 Lyngby, Denmark
}

\section{Summary}

Anodic bonding of Si to Si four inch wafers using evaporated glass was performed in air at temperatures ranging from $300^{\circ} \mathrm{C}$ to $450^{\circ} \mathrm{C}$. Although annealing of $\mathrm{Si} /$ glass structures around $340^{\circ} \mathrm{C}$ for 15 minutes eliminates stress, the bonded wafer pairs exhibit compressive stress. Pull testing revealed maximum bond strengths greater than $50 \mathrm{~N} / \mathrm{mm}^{2}$ and an average bond strength of $30 \mathrm{~N} / \mathrm{mm}^{2}$. The bond strength is independent of both the bonding temperature and the feature size. We observed no fracture at the actual bond interface.

Keywords: anodic bonding, evaporated glass.

\section{Introduction}

Low-cost production of micromechanical devices requires reliable bonding at the wafer scale. Anodic bonding is a candidate because of the relatively low required temperatures $\left(350^{\circ} \mathrm{C}-450^{\circ} \mathrm{C}\right)$ and high mechanical and chemical stability $[1,2]$. Furthermore, anodic bonding is attractive because of its capability of sealing cavities and even filling $18 \mathrm{~nm}$ deep trenches [3]. Processes for anodic bonding of Si to bulk glass and Si to Si using thin glass layers have been developed. Typically Pyrex 7740 or Schott 8330 are used. The thermal expansion of these glasses is matched to the thermal expansion of $\mathrm{Si}$, favoring low stress in the bonded devices. The thin glass films are usually deposited by sputtering. Recently the use of evaporated glass (Schott 8329) for anodic bonding purposes was reported [4]. The deposition rates of evaporated glass are at least three orders of mag- nitude greater than of sputter-deposited glass [2], which favors industrial applications. In this paper we evaluate the evaporated glass and its use for anodic bonding as a function of bonding temperature and fcature sizc.

\section{Experimental}

A $5 \mu \mathrm{m}$ thick sodium-containing boro-silicate glass (Schott 8329) was deposited by electron-beam evaporation onto clean four inch $\mathrm{Si}$ wafers. The wafers were either smooth or contained a test pattern. The base pressure of the vacuum chamber is better than $2 \times 10^{-4} \mathrm{~Pa}$. The deposition rate is proportional to pressure, with $5 \times 10^{-3} \mathrm{~Pa}$ corresponding to a deposition rate of $20 \mathrm{~nm} / \mathrm{s}$.

Secondary ion mass spectrometry (SIMS) was used for compositional analysis of the glass. A stylus-type surface profiler was used for roughness and wafer curvature measurements. Thin-film stress was derived from the wafer curvature.

Annealing and bonding experiments were performed in air on a hot plate. A plate electrode (the hot plate itself) and a three-point load with a weight of $3.25 \mathrm{~kg}$ were used as electrical contacts to the wafer pair during bonding. Bonding was performed at temperatures ranging from $300^{\circ} \mathrm{C}$ to $450^{\circ} \mathrm{C}$. The bonded wafer pairs were inspected using infrared microscopy. Unstructured bonded wafer pairs were submerged in a $28 \mathrm{wt} \% \mathrm{KOH}$ solution at $80^{\circ} \mathrm{C}$ for several hours and exposed to a qualitative wedge test by pressing a razor blade between the wafers. The structured Si wafers contained features approximately $15 \mu \mathrm{m}$ high with a line width varying from 50 to $300 \mu \mathrm{m}$ and a bond 


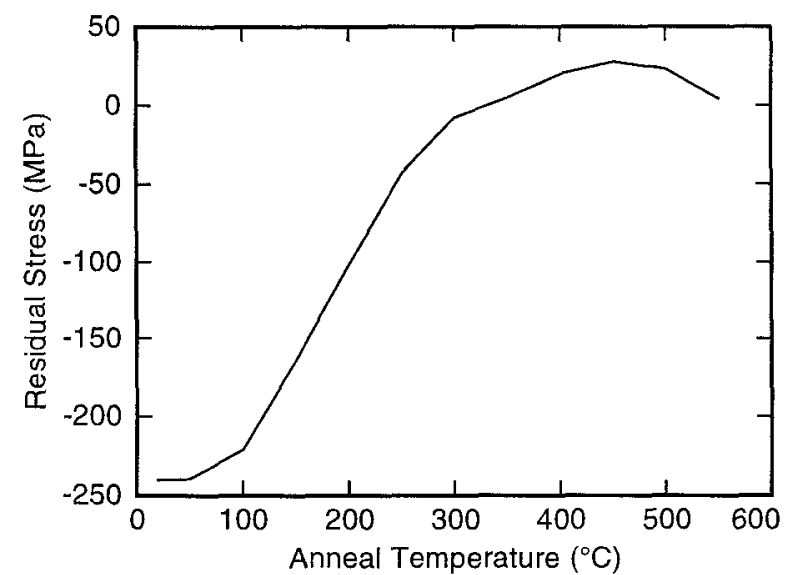

Figure 1: Residual stress of evaporated glass as a function of anneal temperature. After annealing around $340^{\circ} \mathrm{C}$ for 15 minutes in air the glass is free of stress.

area of $3 \mathrm{~mm}^{2}$ per item. Pull tests were performed after dicing the bonded wafers into chips.

\section{Results and discussion}

As compared to Pyrex 7740 and Schott 8330, two types of glass which are frequently used in anodic bonding $[2,5]$, the sodium content of bulk Schott 8329 glass is reduced with a factor of approximately two (maximum $2.1 \mathrm{wt} \%$ ). However, our SIMS measurements show that the deposited thin films are greatly enriched in sodium, which is advantageous for the anodic bonding process. The composition of the glass films appears to be independent of deposition rate in the range $5 \mathrm{~nm} / \mathrm{s}$ to $50 \mathrm{~nm} / \mathrm{s}$.

A stylus type surface profiler was used for roughness and wafer-curvature measurements. Values for the average and root-mean-square roughness below $2 \mathrm{~nm}$ were measured for all deposition rates. The peak roughness was less than $15 \mathrm{~nm}$ for a deposition rate of $20 \mathrm{~nm} / \mathrm{s}$. The roughness of the as-deposited glass films did not change during annealing in air at temperatures up to $500^{\circ} \mathrm{C}$. Residual stress in the evaporated glass films was derived from wafer curvature difference measure-
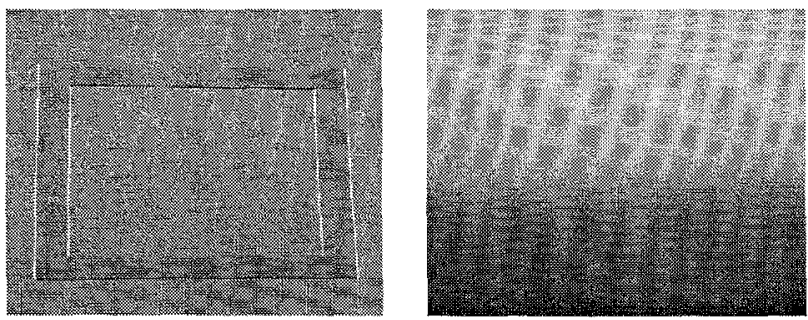

(a)

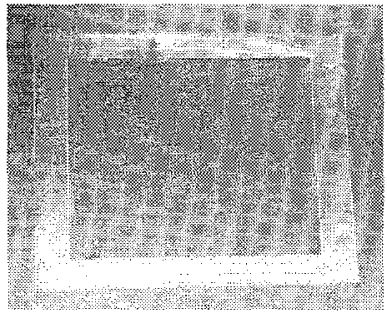

(c)

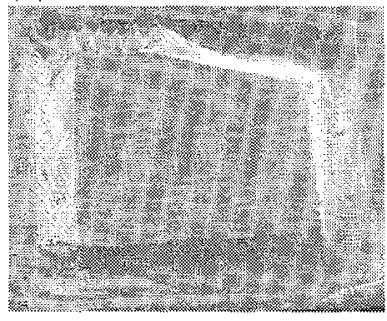

(e) (b)

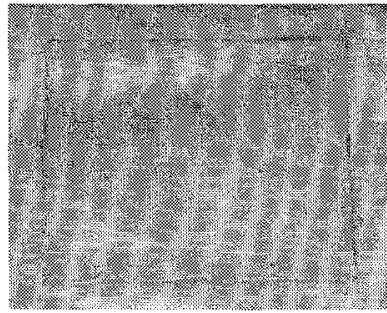

(d)

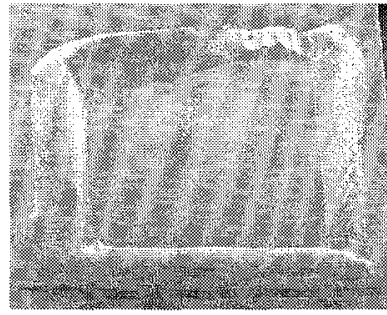

(f)
Figure 2: Pull test of bonded structures. A $15 \mu \mathrm{m}$ high structure in $\mathrm{Si}$ (a). The square measures $3 \times 3 \mathrm{~mm}^{2}$ and the line width is $300 \mu \mathrm{m}$. The structures are bonded to plane Si covered with glass (b). After bonding and pulling the structure apart, the Si structures either remain intact (c) and the glass is removed from its original substrate (d), or the Si is torn apart (e) and transferred to the glass (f).

ments. Without annealing the films exhibit a high compressive stress (typically around $225 \mathrm{MPa}$ ), as can be seen in Fig. 1. This initial stress is independent of deposition rate. Upon annealing in air for $15 \mathrm{~min}$ at temperatures above $100^{\circ} \mathrm{C}$ and cooling down to room temperature the stress is relieved. Annealing around $340^{\circ} \mathrm{C}$ results in stressfree films.

During bonding in air in the temperature range from $300^{\circ} \mathrm{C}$ to $450^{\circ} \mathrm{C}$, typically a current flow was observed above a voltage of $15 \mathrm{~V}$. Electrical breakthrough of the $5 \mu \mathrm{m}$ thick glass layer usually occurred above $100 \mathrm{~V}$. We observed a maximum cur- 
rent up to $1 \mathrm{~mA}$ within $1 \mathrm{~s}$ after a voltage increase. Thereafter, the current drops rapidly and stabilizes at $0.005 \mathrm{~mA}$ after approximately $15 \mathrm{~min}$.

Inspection of bonded wafer pairs with an IRsensitive camera reveals that a bonded area of more than $95 \%$ of the total four inch wafer area can be achieved routinely. Although annealing of $\mathrm{Si}$ /glass structures around $340^{\circ} \mathrm{C}$ eliminates stress, the glass of the bonded wafer pairs exhibits compressive stress. This is derived from the wafer curvature after bonding of wafers with different thicknesses. This residual stress is observed for all bonding temperatures. This issue requires further investigation.

Wafer pairs bonded at $450^{\circ} \mathrm{C}$ were exposed to a $28 \mathrm{wt} \% \mathrm{KOH}$ solution at $80^{\circ} \mathrm{C}$ for 6 hours. A slight attack of the glass was observed at the outermost edge, whereas the central area retained its initial bond strength. A qualitative measure of the bond strength was obtained by pressing a razor blade between the bonded wafers, which were found impossible to separate without breaking.

Pull test experiments on chips diced from the structured wafer pairs quantified the bond strength. A typical example is shown in Fig. 2, which shows a rectangular test structure before bonding ( $a$ and $b$ ) and after pull testing. Fracturing at the bond interface was never observed. Instead, either the glass was transferred to the $\mathrm{Si}$ structure (c and d), or the Si structure itself was fractured (e and $f$ ).

The average bond strengths obtained from the pull test are depicted in Figs. 3 and 4 . The average values are around $30 \mathrm{~N} / \mathrm{mm}^{2}$ with a standard deviation of $5 \mathrm{~N} / \mathrm{mm}^{2}$. Maximum values in excess of $50 \mathrm{~N} / \mathrm{mm}^{2}$ were observed. From Fig. 3 it is observed that the bond strength is independent of bonding temperature. In Fig. 4 the data are rearranged and it can be seen that, within the error limits, the bond strength is independent of the line width of the test structures as well.

The bond strengths reported in this paper compare to those reported in Ref. [4], where the same type of evaporated glass was used and bonding was

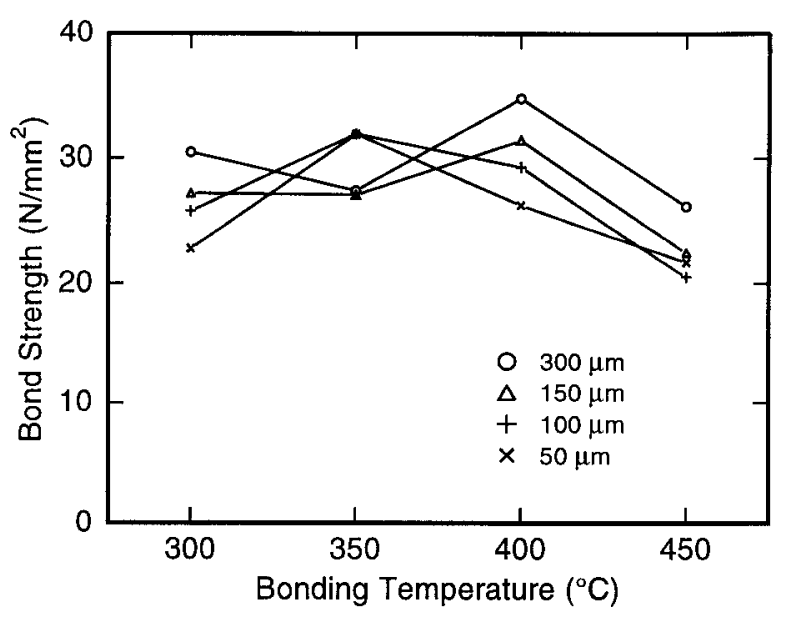

Figure 3: Bond strength versus bonding temperature for various line widths of the bonded areas. The standard deviation of the bond strength is approximately $5 \mathrm{~N} / \mathrm{mm}^{2}$. The bond strength is independent of bonding temperature.

performed at $400^{\circ} \mathrm{C}$ and $450^{\circ} \mathrm{C}$ after pre-annealing between $450^{\circ} \mathrm{C}$ and $500^{\circ} \mathrm{C}$. According to our results the pre-annealing step seems not to be necessary. However, this may be related to a peak roughness less than $15 \mathrm{~nm}$ of the glass films deposited at a rate of $20 \mathrm{~nm} / \mathrm{s}$, which is considerably lower than the value of $100 \mathrm{~nm}$ for films deposited at a rate of $67 \mathrm{~nm} / \mathrm{s}$ [4].

In this work we show that the temperature range for successful bonding using evaporated glass can be extended at least down to $300^{\circ} \mathrm{C}$. Although anodic bonding of Si to glass substrates is performed successfully in the range from $300^{\circ} \mathrm{C}$ to $450^{\circ} \mathrm{C}$, temperatures above $400^{\circ} \mathrm{C}$ are usually applied to Si-to-Si anodic bonding. We did not observe a relation between bond strength and bonding temperature as reported in $[6,7]$ for bonding of Si to bulk Pyrex. As reported in [7], by raising the bonding temperature from $300^{\circ} \mathrm{C}$ to $450^{\circ} \mathrm{C}$, the bond strength increases and reaches the strength of the Pyrex glass substrate. Failure of the bond then occurs when the bulk glass fractures $[7,8]$. In general, the strength of the anodic bond using evaporated glass $\left(>30 \mathrm{~N} / \mathrm{mm}^{2}\right.$ ) is greater than a bond where sputtered glass [2] or bulk glass $[6,8]$ is used 


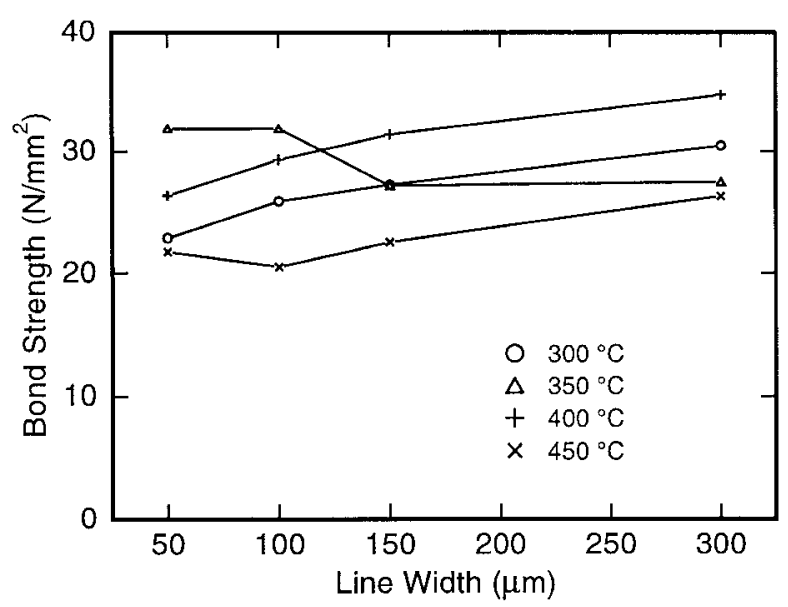

Figure 4: Bond strength versus line width for various bonding temperatures (same data as in Fig. 3). The bond strength is independent of line width.

$\left(\leq 25 \mathrm{~N} / \mathrm{mm}^{2}\right)$.

\section{Conclusions}

Evaporation of Schott 8329 glass for anodic bonding purposes was done at a rate of $20 \mathrm{~nm} / \mathrm{s}$. This is a fast deposition method which favors industrial applications. Low stress can be achieved by annealing at $340^{\circ} \mathrm{C}$ for $15 \mathrm{~min}$. Full area bonding of four inch $\mathrm{Si}(100)$ wafers was obtained at temperatures between $300^{\circ} \mathrm{C}$ and $450^{\circ} \mathrm{C}$ and between $15 \mathrm{~V}$ and $100 \mathrm{~V}$. The glass of the bonded wafer pairs exhibit compressive stress. The bond is stable against $\mathrm{KOH}$ etching $\left(28 \mathrm{wt} \%, 80^{\circ} \mathrm{C}\right)$ for at least six hours. The average bond strength of $30 \mathrm{~N} / \mathrm{mm}^{2}$ is higher than for bonding of Si to bulk glass or Si to Si using sputtered glass. Furthermore, samples subjected to a pull test show that the glass-to-Si bond interface remains intact. The bond strength is independent of bonding temperature in the range $300^{\circ} \mathrm{C}$ to $450{ }^{\circ} \mathrm{C}$ and independent of line width of the test structures. Since no degradation of bond strength is observed in the above-mentioned temperature range, lower bonding temperatures may be possible.
Acknowledgements. The authors would like to thank Dr. Siebe Bouwstra for helpful discussions and a critical reading of the manuscript. This work was performed as part of the 'Materials Centre for Microelectronics' and 'Materials for Advanced Micromechanical Packaging' programs, supported by the Danish Agency for Trade and Industry, The Danish Natural Science Research Foundation, and the Danish Technical Science Research Foundation under the Materials Development Program.

\section{References}

[1] M. Esashi, Microsystem Technol. 1, 2 (1994).

[2] A. Hanneborg, M. Nese, and P. Øhlckers, J. Micromech. Microeng. 1, 139 (1991).

[3] H. Baumann, S. Mack, and H. Münzel, Electrochemical Society Proceedings 95, 471 (1995), in Proceedings of the Third International Symposium on Semiconductor Wafer Bonding: Physics and Applications.

[4] P. Krause et al., The $8^{\text {th }}$ international conference on solid-state sensors and actuators, Eurosensors IX. Digest of technical papers. (Foundation for Sensor and Actuator Technology, Stockholm, Sweden, 1995), pp. 228-231.

[5] J. Berenschot, J. Gardeniers, T. Lammerink, and M. Elwenspoek, Sensors and Act. A 41-42, 338 (1994).

[6] A. Cozma and B. Puers, in Micro Mechanics Europe 1994 Workshop Digest (Consorzio Pisa Ricerche, Pisa, Italy, 1994), pp. 40-43.

[7] D. Hurd, R. Caretta, and W. Gerberich, J. Mater. Res. 10, 387 (1995).

[8] J. P. Rasmussen, Master's thesis, Mikroelektronik Centret, Technical University of Denmark, bldg. 345-east, DK-2800 Lyngby, Denmark, 1994, in Danish. 